\title{
OLHARES SENSÍVEIS EM ESTUDO DE CAMPO AO MUSEU SOLAR MONJARDIM: MEMÓRIA E FORMAÇÃO HISTÓRICA
}

\author{
MIRADAS SENSIBLES EN VISITAS AL MUSEO SOLAR MONJARDIN: MEMORIA Y \\ FORMACIÓN HISTÓRICA
}

\author{
SENSITIVE EYES ON VISITS TO THE MONJARDIM SOLAR MUSEUM: MEMORY \\ AND HISTORICAL FORMATION
}

Regina Celi Frechiani BITTE ${ }^{1}$

Sônia Maria dos SANTOS ${ }^{2}$

RESUMO: Objetiva-se refletir sobre as teorias e metodologias que perpassam a formação histórica, encetadas a partir dos estudos de campo realizadas no museu Solar Monjardim com alunos do Curso de Pedagogia da Universidade Federal do Espírito Santo. Na busca por mapear e despertar alternativas que propiciem os olhares sensíveis para aspectos históricoculturais presentes em museus, adotou-se a metodologia qualitativa de pesquisa. Utilizamos vários fragmentos dos debates realizados em sala de aula, da observação ao espaço museal e dos relatos, produzidos pelos alunos após o estudo de campo. Os resultados das visitas ao museu demonstram uma leitura a "contra pelo" e podem ser vistos como trama tecida a partir da sensibilidade dos alunos ao que lhes foi apresentado. Em suas competências narrativas aparecem os seus próprios sentidos históricos que atribuem em relação ao museu, à memória e à história.

PALAVRAS-CHAVE: Formação histórica. História. Memória. Museu.

RESUMEN: El objetivo es reflexionar sobre las teorías y metodologías que permean la formación histórica, iniciadas a partir de estudios de campo realizados en el museo Solar Monjardim con estudiantes del Curso de Pedagogía de la Universidad Federal de Espírito Santo. En la búsqueda de mapear y despertar alternativas que brinden visiones sensibles a los aspectos históricos y culturales presentes en los museos, se adoptó la metodología de investigación cualitativa. Utilizamos varios fragmentos de los debates realizados en el aula, desde la observación al espacio del museo y los informes elaborados por los estudiantes después del estudio de campo. Los resultados de las visitas al museo demuestran una lectura "contra la piel" y se puede ver como una tela tejida a partir de la sensibilidad de los estudiantes hacia lo que se les presenta. En sus habilidades narrativas aparecen sus propios significados históricos en relación con el museo, la memoria y la historia.

PALABRAS CLAVE: Formación histórica. Historia. Memoria. Museo.

\footnotetext{
${ }^{1}$ Universidade Federal do Espírito Santos (UFES), Vitória - ES - Brasil. Professora Associada I e Docente do Centro de Educação. Doutorado em Educação (UFES). ORCID: https://orcid.org/0000-0001-6819-3900. E-mail: bitteregina@gmail.com

${ }^{2}$ Universidade Federal de Uberlândia (UFU), Uberlândia - MG - Brasil. Professora Titular Aposentada da Faculdade de Educação (UFU). Doutorado em Educação (PUC-SP). ORCID: https://orcid.org/0000-0002-72171576. E-mail: soniaufu@gmail.com
}

RIAEE - Revista Ibero-Americana de Estudos em Educação, Araraquara, v. 16, n. 4, p. 2888-2902, out./dez. 2021. e-ISSN: 1982-5587 DOI: https://doi.org/10.21723/riaee.v16i4.14533 
ABSTRACT: The objective is to reflect on the theories and methodologies that permeate historical formation, initiated from field studies carried out at the Monjardim Solar Museum with students from the Pedagogy Course at the Federal University of Espirito Santo. In the search to map and awaken alternatives that provide sensitive views to historical and cultural aspects present in museums, the qualitative research methodology was adopted. We used several fragments of the debates held in the classroom, from observation to the museum space and the reports produced by the students after the field study. The results of the visits to the museum demonstrate a "rough" reading and can be seen as a fabric woven from the students' sensitivity to what was presented to them. In their narrative skills, their own historical meanings appear in relation to the museum, memory and history.

KEYWORDS: Historical formation. Story. Memory. Museum.

\section{Introdução}

O presente texto expõe os resultados da pesquisa relacionada ao exercício da nossa prática docente como formadora de formadores na disciplina de 'História: Conteúdo e Metodologia', no curso de licenciatura em Pedagogia da Universidade Federal do Espírito Santo (UFES). Tem por objetivo geral refletir sobre as teorias e metodologias que perpassam a formação histórica, encetados a partir dos estudos de campo realizados no museu Solar Monjardim.

Perseguindo nosso objetivo, procuramos investigar quais os saberes que os alunos de Pedagogia carregam em sua formação, como dispositivos desencadeadores de práticas culturais na relação museu-escola, memória e patrimônio com vista à formação histórica, alinhavando sensibilidades e análise crítica sobre a vida social, material e cultural dos mesmos.

Partimos do pressuposto de que na construção de uma formação histórica, o conhecimento histórico não se processa diretamente entre o sujeito e o objeto a ser conhecido, sendo que entre eles existe a ação mediadora do professor, a ação mediada da linguagem, de signos e ferramenta (SIMAN, 2003).

Assim, destacamos o museu como espaço mediador na construção do conhecimento histórico, como um dos lugares onde podem ser guardados vários objetos (signos e ferramentas) que falam de uma história individual e coletiva, enquanto parte de uma comunidade que viveu em determinado tempo e espaço histórico. Nesse sentido, o contato com os objetos forma, às vezes, um discurso complexo a partir do olhar dos sujeitos, e esses discursos podem ser mediados pelo professor, suscitando questões relativas à construção de uma memória e de representações do passado. 
Conforme Meneses (1992), a memória refere-se mais ao presente que ao passado. Portanto, retirar a sua dimensão de passado seria não a entender como força do presente. Isto é, sem memória não há presente humano, e muito menos futuro. Dessa forma, a memória giraria em torno de um dado básico: a mudança. Com esse entendimento sobre a relação entre a memória e a vida presente, foram desenvolvidas as reflexões a partir dos estudos de campo realizadas ao museu, considerando a constituição da memória como possibilidade de reflexão sobre o passado, intimamente relacionada com as transformações do presente.

Em função do tema e das questões a ele referentes, foi adotada uma metodologia qualitativa de pesquisa, cuja abordagem se baseou na história cultural, que busca “[...] identificar os modos como em diferentes lugares e momentos uma determinada realidade social é construída, pensada e dada a ler" (CHARTIER, 1990, p. 17). No nosso estudo de campo específico pensamos a história a partir do cotidiano da família que vivia no casarão, hoje denominado de Museu Solar Monjardim, no século XIX no Espírito Santo e, quem sabe, ir além dele.

Nos balizamos também no referencial teórico da história cultural, que se tornou o paradigma para podermos compreender as práticas, apropriações e representações que são realizadas pelos alunos do curso de Pedagogia, entendendo as representações "[...] não como simples reflexos verdadeiros ou falsos da realidade, mas como entidades que vão construindo as próprias divisões do mundo social" (CHARTIER, 2009, p. 7).

Assim, na confecção do texto utilizamos de vários fragmentos decorrentes dos debates realizados em sala de aula, da observação ao espaço museal e dos 83 relatos escritos, produzidos pelos alunos após o estudo de campo, realizados com cinco turmas do curso de Pedagogia no decorrer dos anos de 2017, 2018 e 2019, contemplando os turnos matutino e noturno. Para confecção deste trabalho os fragmentos dos relatos dos alunos foram identificados no texto com nomes fictícios.

Ao acompanhar os estudos de campo ao museu objetivamos identificar: quais as relações estabelecidas com o espaço museal; como se posicionam em relação às suas memórias e os mediadores culturais ali presentes; e quais memórias são suscitadas, ressignificadas e partilhadas nas experiências vivenciadas.

Partimos, pois, do princípio de que é de grande relevância, para o meio acadêmico e para a prática educativa como um todo, investigar, a partir da confluência dos paradigmas da História Cultural, como se tem constituído a formação histórica, tomando por base a relação que se estabelece entre museu, memória e história. 


\section{Preparando para a visita: curiosidades e ansiedades}

A disciplina 'História: Conteúdo e Metodologia' é oferecida no sétimo período para os alunos do curso de Pedagogia. Na ementa do Programa de Disciplina estão previstos os estudos relacionados ao patrimônio e à memória. Para contemplar esse conteúdo dedicamos uma unidade de ensino intitulada ' $\mathrm{O}$ uso de documentos/Fontes no ensino de História', que tem como objetivo discutir a memória e o patrimônio a partir dos arquivos, bibliotecas, museus, dentre outros. Fizemos a opção pelo museu. Os estudos de campo foram realizados com quatro turmas no decorrer dos anos de 2017 a 2019, ao Museu Solar Monjardim, localizado no Bairro Jucutuquara, na Avenida Paulino Muller S/N, em Vitória, no estado do Espírito Santo.

Para subsidiar os estudos de campo, aulas foram destinadas para as leituras e discussões sobre memória, patrimônio e museu, ancoradas nos textos de Oriá (2013), Carvalho e Porto (2012), e Siman (2003). Nessas discussões, fomos pinçando quais conhecimentos os alunos trazem em suas bagagens culturais relacionados à memória, patrimônio, história e museu. $\mathrm{Na}$ confecção deste trabalho as narrativas dos sujeitos são identificadas por nomes fictícios.

Em relação à memória, sobressaíram as seguintes vozes dos alunos nas discussões realizadas em sala de aula: 'A memória serve para aprender com o que passou e não repetir os mesmos erros'; 'Sem memória não saberemos sobre o nosso passado' e a 'Memória não se modifica, ela nos fala de algo do passado'. A partir dessas falas fizemos os seguintes questionamentos: Será que a memória pode ser ressignificada? Será que ela pode ser um vínculo entre a sucessão de gerações e o tempo histórico? Se positivo, será que ao fazer esse vínculo a memória não está sendo repensada, reconstruída a partir de inquietações que vivenciamos no presente?

Ao instigar e inquietar os alunos, nosso objetivo foi o de pensar, formular e discutir com os mesmos o conceito de memória. A partir das falas que iam surgindo alinhavadas às leituras que fizeram, o conceito de memória foi sendo construído coletivamente. Inicialmente, evocamos Meneses (2000), que trabalha a memória como elaboração do presente para responder a solicitações do presente (MENESES, 2000, p.93). Assim, fomos conversando e ampliando a nossa compreensão. Avançando no debate, Clara chama a atenção que:

[...] a memória é muito importante para a preservação de nossa identidade cultural. Sem ela não é possivel saber da nossa história passada, das experiências vividas e das lutas para chegar onde chegamos. Veja a questão das cotas para entrar nas universidades. Se queremos entender o processo 
temos que buscar pelas memórias de libertação de nosso povo (CLARA, 2018).

Assim, chegamos à conclusão de que a memória é uma ação encontrada pelos sujeitos de atualização e interpretação de experiências que possam vir a corroborar com inquietações vivenciadas no presente.

Aproveitamos o calor do debate e, no intuito de ampliar as reflexões, envolvendo as representações sobre o museu, os alunos foram questionados sobre o museu e sobre como o definiriam. Assim, Rosângela respondeu:

\begin{abstract}
Acharam que eu ia falar que o museu é lugar de guardar coisa velha, né. É, também. Mas é um lugar poderoso que fala da história de pessoas importantes, poderosas. Essa era uma idéia que eu tinha, antes de ler o texto de Siman [ela está se referindo ao texto indicado para leitura]. Mas, depois eu parei para pensar e vi que museu é um lugar legal, que guarda objetos, velhos na verdade, mas dependendo das perguntas que fizermos, nós saberemos um pouco da história e da memória. Ele também e um lugar de conversar, de aprender e lúdico (ROSANGELA, 2018).
\end{abstract}

A partir da fala da Rosângela, convidei-os a fazerem outra conexão: a de museu com o patrimônio. O que podemos inferir dos textos lidos em relação ao patrimônio? De forma muito tímida Fátima no fundo da sala externou em sua fala que:

Pelo que entendi nem sempre na nossa história tudo foi preservado. O que foi preservado foi a memória, o patrimônio da elite, dos poderosos. Sempre tive a idéia de museu como algo monumental, grandioso. E quando comecei a ler os textos vi que o museu não era só isso. Que também pode ser lugar prazeroso para a aprendizagem (FÁTIMA, 2018).

Começamos nosso diálogo destacando que hoje a preservação do patrimônio histórico é vista, principalmente, como uma questão de cidadania, de interesse de todos. Mas nem sempre foi assim. No passado a preservação estava restrita a bens materiais de grande valor arquitetônico e que fossem representantes de fatos notáveis de nossa história. Essa ideia de preservação baseou-se no Decreto-lei $n^{\circ} 25 / 37$, que vigorou em nosso país até a Constituição de 1988. Tal decreto, em seu art. $1^{\text {o }}$, traz o conceito de 'patrimônio histórico e artístico' como sendo aquele que:

Constitui o patrimônio Histórico e artístico e nacional o conjunto de bens móveis e imóveis existente no país e cuja conservação seja de interesse público, quer por sua vinculação a fatos memoráveis da História do Brasil, quer por seu excepcional valor histórico ou etnográfico, bibliográfico ou artístico (BRASIL, 1988). 
Para Oriá (2013), priorizou-se o patrimônio material, edificado e arquitetônico, em detrimento de outros tantos patrimônios que foram relegados ao esquecimento. Essa forma perversa de preservação foi inculcada em nossa memória. O que não está relacionado a fatos memoráveis de nossa história não é digno de ser preservado, não é memória e, consequentemente, não faz parte do nosso patrimônio. Dentro desse entendimento, preservaram os casarões e relegaram ao esquecimento as senzalas.

Se, por um lado, a implementação de leis em defesa do Patrimônio Histórico representou um avanço no campo da preservação da memória social no Brasil, por outro lado, seus fundamentos acabaram provocando a expropriação da memória e da história da grande maioria da população, que não se viu reconhecida em obras suntuosas como solares, casarões, igrejas, câmaras municipais, fortificações, entre outros edifícios. A população ficou assim desprovida de memória coletiva que lhes permitisse a consciência histórica (FENELON, 1992).

As pressões da sociedade civil por meio de variadas associações como o Instituto de Arquitetos Brasileiros (IAB), a Associação dos Geógrafos Brasileiros (AGB) e a Associação Nacional de História (ANPUH) contribui fortemente para a nova mudança na atual Constituição brasileira, que adota a terminologia 'patrimônio cultural' em substituição à de 'patrimônio histórico e artístico'. (ORIÁ, 2013)

Assim, a atual Constituição em seu artigo 2016, Seção II - DA CULTURA define:

Constituem patrimônio cultural brasileiro os bens de natureza material e imaterial, tomados individualmente ou em conjunto, portadores de referência à identidade, à ação, à memória dos diferentes grupos formadores da sociedade brasileira, nos quais se incluem:

I - as formas de expressão;

II - os modos de criar, fazer e viver;

III - as criações científicas, artísticas e tecnológicas;

IV - as obras, objetos, documentos, edificações e demais espaços destinados às manifestações artístico-culturais;

$\mathrm{V}$ - os conjuntos urbanos e sítios de valor histórico, paisagístico, artístico, arqueológico, paleontológico, ecológico e científico (BRASIL, 1988).

Como podemos observar, o texto da Constituição de 1988 preserva todos os bens, sejam naturais ou culturais, tangíveis ou intangíveis, materiais ou imateriais, e entende-se que todos esses bens constituem o patrimônio cultural do país, desde que sejam portadores da identidade e da memória constituinte da nação brasileira.

Dessa forma, trazemos para o nosso debate os olhares atentos que devemos ter ao estudo de campo aos museus, como espaços tanto de memória como, também, de esquecimento. Abordamos o museu como espaço que representa disputas entre narrativas. 
Para Pollack (1989), distinguir entre conjunturas favoráveis ou desfavoráveis às memórias marginalizadas é de saída reconhecer a que ponto o presente colore o passado. Para o autor, conforme as circunstâncias, ocorre a emergência de certas lembranças, a ênfase é dada a um ou outro aspecto "[...] assim, também, há uma permanente relação entre o vivido e o aprendido, o vivido e o transmitido" (POLLACK,1989, p. 9).

De certa forma, trazer o passado vivido como opção de questionar as tramas sociais existentes no presente vai depender das perguntas que estabelecemos com o discurso que nos forem apresentados nos museus, bem como as perguntas que podemos fazer aos objetos ali presentes. Por isso o nosso olhar atento quando do estudo de campo ao museu.

As narrativas dos nossos alunos desvelaram que o museu aparece como espaço de aprendizagem. Concordei e complementei que pode sim ser um lugar de aprendizado histórico e formação histórica, inclusive, na perspectiva de Rüsen (2007), como capacidade de uma determinada constituição de narrativa de sentido, cujo processo de aprendizado se operacionaliza por meio da experiência, interpretação e orientação pois:

[...] o aprendizado pode ser considerado histórico quando produz uma ampliação da experiência do passado humano, um aumento da competência para interpretação histórica dessa experiência e a capacidade de inserir e utilizar interpretações históricas no quadro de orientações para a vida prática (RÜSEN, 2007, p. 110).

E o que seria essa orientação para a vida prática? Seria construir sentido histórico a partir da interpretação de seu mundo e de si mesmo, defendidas por Rüsen como competência narrativa. Assim, as narrativas construídas pelos alunos após os estudos de campo realizados no museu sinalizam também os seus próprios saberes em relação à história e à memória que os circundam e as relações que estabelecem com o museu.

Outra questão importante que foi destacada se refere à formação histórica. A experiência histórica no estudo de campo está relacionada à forma como cada um compreende a temporalidade histórica, como cada um se relaciona com passado, presente e futuro, como ele colore esse passado no presente e como corrobora o futuro. Ainda sobre este contato com a experiência do passado no processo de formação, recoloca-se a discussão objetividade versus subjetividade. Ou seja, o contato com a experiência do passado, além de ampliar a orientação histórica por meio de fatos passados, num processo temporal em que passado e presente são constantemente contrastados, garante aos sujeitos novos espaços internos em perceber o 'eu' num processo de ganho de liberdade e de reconhecimento do 'outro' (BAROM; CERRI, 2011).

RIAEE - Revista Ibero-Americana de Estudos em Educação, Araraquara, v. 16, n. 4, p. 2888-2902, out./dez. 2021. e-ISSN: 1982-5587 
Concluindo, provisoriamente, nossas primeiras impressões sobre museu, memória, história, patrimônio e formação histórica, apresentarei de forma bem sucinta o museu Solar Monjardim, onde foi realizado o estudo de campo. As informações históricas foram retiradas do documento 'Protocolo de Visitação do Museu Solar Monjardim', que é cedido a todos os professores quando agendam seus estudos de campo, com o objetivo de contribuir para o aprendizado.

O Museu Solar Monjardim tem hoje uma área de pouco mais de $16.000 \mathrm{~m}^{2}$, terreno que restou da antiga Fazenda Jucutuquara. No século XVI, a propriedade pertenceu aos Jesuítas e suas terras já eram cultivadas. Porém, com a expulsão dos Jesuítas, ocorrida em 1759 , houve mudanças relativas à posse das terras por eles administradas.

Na segunda metade do século XVIII, a antiga Fazenda Jucutuquara já pertencia a Gonçalo Pereira Porto, abastado comerciante e rico proprietário rural. Do casamento de sua filha Francisca de Sampaio Pereira Porto com o Capitão-Mor Francisco Pinto Homem de Azevedo, a Fazenda Jucutuquara passa a pertencer a este último, por meio de dote de casamento. Tiveram uma filha, D. Ana Francisca Maria da Penha Benedita Homem de Azevedo, que se casou com o Coronel José Francisco Monjardim, que recebeu a casa e a fazenda em forma de dote. A partir de então, seus descendentes passaram a utilizar a casa até a década de 1940.

$\mathrm{Na}$ fazenda Jucutuquara se cultivava cana-de-açúcar e algodão, além de diferentes produtos agrícolas para a subsistência. Parte de sua área também se destinava à criação de gado. Além do engenho de açúcar, a fazenda possuía indústrias caseiras, tais como a fabricação de farinha de mandioca, fiação de algodão, extração do azeite de baga, tachadas de doces, entre outros produtos.

A partir da década de 1940, abrigou diferentes museus, até que em $1^{\circ}$ de agosto de 1980 foi reaberta e recebeu o nome de Museu Solar Monjardim, com a conceituação de reconstituir uma residência rural e o contexto sociocultural de uma família abastada do século XIX.

\section{Andarilhos no Museu Solar Monjardim}

Já no espaço do museu Solar Monjardim, nossos olhares se voltaram para identificar como os estudantes de Pedagogia arquitetaram suas memórias a partir da exposição que lhes era apresentada. Várias abordagens temáticas são apresentadas pelo museu, que contemplam conteúdos relacionados com: a relação do homem com a natureza; História de Vitória; hábitos 
alimentares; higiene e saúde; religiosidade; meios de comunicação; meios de transporte; relação de trabalho, entre outros. Conforme salienta o monitor do museu, a ênfase dada à exposição depende, também, dos objetivos explicitados pelo professor.

O estudo de campo começou pela sala de visitas e foi se adentrando pelos outros espaços, fazendo os percursos estipulados pelo museu e os feitos pelos alunos da Pedagogia. Esses percursos foram feitos tanto no ato de caminhar no espaço físico como também no ato imaginário.

Se em alguns momentos os percursos se mostraram de forma a trabalhar certas histórias em detrimento de outras, os alunos fizeram seus atalhos, com inquietações e questionamentos, frente às histórias que lhes foram apresentadas. $\mathrm{O}$ museu, ao retratar o cotidiano de uma família abastada, os instigou a pensar como viviam outras famílias.

Assim, a partir dos objetos observados e da exposição do monitor do Museu, surgiram vários questionamentos tais como em relação ao trabalho, o papel da mulher e a alimentação. $\mathrm{Na}$ realidade, os alunos foram criando sentidos diversos dos apresentados pelo museu. Em alguns momentos, esses sentidos foram produzidos pela ausência. Isso ficou registrado quando Alice questionou por que não se falava, ou pouco se falava, da presença do negro no casarão, pois eram eles quem desenvolviam os trabalhos domésticos. Conforme Chartier (1990), a representação também se faz pela ausência.

Os efeitos dos sentidos produzidos pelos alunos a partir dos objetos que lhes foram apresentados mobilizaram sentimentos e memórias. Produziram significados vários para a materialidade, fizeram conexões com sua trajetória pessoal e social. Além disso, os alunos fizeram os seus próprios mapas perceptivos. Fizeram relações do passado com o presente, perceberam as rupturas, permanências, as continuidades e as descontinuidades no processo história.

Conforme iam adentrando no espaço os burburinhos aumentavam. Ao fazerem seus movimentos perceptivos iam construindo os mapas de significação que eram compartilhados entre eles. Por isso, registramos uma 'danação' (RAMOS, 2004) causada não só pelos alunos, mas também pelos objetos em exposição. Em vários momentos a exposição tocou os alunos. A partir de situações vivenciadas no presente, os alunos estabeleceram relações com o que não vivenciaram. Percebemos que a movimentação que eles faziam não tinha como objetivo viver o passado, buscava-se a história através dos objetos, abrindo inúmeras possibilidades de interpretação (RAMOS, 2004).

Ao buscar essas inúmeras possibilidades de interpretação, os alunos fizeram conexões com outros saberes que dominavam. Como bem nos lembra Tardif (2012), os saberes da 
formação docente são constituídos pelo amálgama dos diversos saberes: os que derivam da contribuição que as ciências humanas oferecem à educação e aos saberes pedagógicos, e são transmitidos pelas instituições de formação de professores; os saberes das disciplinas incorporam os saberes sociais, definidos e selecionados pela instituição universitária e correspondem aos diversos campos de conhecimento; os saberes curriculares se apresentam como forma de programas curriculares e correspondem aos discursos, objetivos, conteúdos e métodos; e os saberes da experiência, por sua vez, são constituídos no exercício da prática cotidiana da profissão, num contexto de múltiplas interações. Em seus mapas perceptivos os alunos articularam as reflexões feitas em sala de aula com os saberes dos museus, com os saberes específicos e os demais saberes apontados por Tardif (2012).

Dessa forma, o museu deixa de ser apenas um recurso metodológico e se torna parte integrante do processo de aprendizagem histórica e formação histórica, na medida que os alunos o percebem como lugar de preservação, divulgação e pesquisa. E, por que não dizer, de entretenimento?

O estudo de campo tornou-se uma possibilidade de formação acadêmica e profissional, indo além do espaço escolar. Exemplifica bem essa reflexão a narrativa de Ana ao despedir-se dos monitores do museu:

Essa visita foi uma experiência incrível e que será válida no meu futuro como professora, pois pude compreender ainda melhor a importância da História e de uma professor/professora que saiba trabalhá-la, para que seus alunos consigam compreender o que e o porquê das coisas serem colocadas como são e como acontecem (ANA, 2017).

A conclusão dos trabalhos de nossos estudos de campo terminava sempre com um delicioso café da manhã (foi combinado que levássemos, bebidas, biscoitos, bolos e frutas) em lugar apropriado no quintal do Museu Solar Monjardim. Afinal, o museu é também lugar de confraternização e alegria!

\section{O que dizem os relatos sobre as experiências vivenciadas}

Os fragmentos de relatos dos estudos de campo que passo a descrever são produções de sentido histórico construídas a partir das interpretações que os alunos fazem de seu mundo e de si mesmo, definida por Rüsen (2007) como competência narrativa. Essa competência narrativa, por sua vez, é sintetizadora da consciência histórica, que tem como pilar a experiência do passado, a interpretação desse passado e o sentido produzido a partir dessa 
interpretação, conforme já descrevemos anteriormente. Assim, os alunos teceram as suas narrativas históricas.

Ao ler os relatos identificamos que várias questões em relação à concepção de história, de museu, de memória e a relação museu/escola que foram discutidas em sala de aula são retomadas.

Destacamos em um dos relatos como a aluna percebe a versão histórica apresentada pelo monitor de museu e da organização de exposição dos objetos:

As leituras anteriores realizadas me proporcionou um novo olhar ao chegar ao museu e verificar que a maioria das histórias que ali eram apresentadas e dos objetos, referiam-se a famílias abastadas, de uma classe fortemente estabelecida, e que a história dos escravos e sua trajetória eram pouco relatadas, fato este que me estimulou para a busca de novas histórias, aquelas narradas por aqueles que por séculos foram invisibilizados (VITÓRIA, 2018).

O fragmento referenciado nos remete aos "protocolos de escritas e leituras" que "[...] remonta aos elementos que determinado autor dissemina pelo texto de modo a assegurar a correta interpretação que deveria dar a ele" (CHARTIER, 1996, p. 10). Trata-se de uma leitura desejada que se espera que seja realizada. A aluna vai além desse protocolo. A partir do que é exposto ela faz outras leituras e chega a suas conclusões: a busca por outras histórias, daqueles que pouco são falados ou representados nos museus.

Aos poucos os alunos vão percebendo que, em alguns momentos, o discurso presente no museu tangencia a heterogeneidade e a diversidade que deve compor a formação histórica. Fala-se muito da história do homem branco, em detrimento das demais.

Em um outro relato, o museu é tomado para além do recurso metodológico e visto como local de pesquisa, para trabalhar a temporalidade histórica com seus futuros alunos, fazendo o entrelace entre memória e história.

\footnotetext{
Naquele pequeno espaço conseguimos identificar diversas temporalidades históricas que passaram, mas que ainda permanecem, através das representações ali presentes (objetos, pinturas) que permitem ao aluno construir crítica e automaticamente, sua memória histórica, através da visualização e da vivência naquele espaço museal, visto que não estiveram presentes naquela determinada época (CÉLIA, 2018).
}

Para Ramos, a exposição deve tocar os visitantes por meio de certos arranjos da memória, da afetividade que compõe o ato de lembrar aquilo que não vivemos, mas que de alguma forma mexe conosco (RAMOS, 2004, p. 38). A aluna foi tocada pela exposição. Ela não viveu aquele momento e nem os seus futuros alunos, mas ambos poderiam aprender por 
meio dos objetos expostos, pois eles falam de um determinado tempo histórico, são portadores de memórias e de histórias prenhes por serem descobertas e narradas.

Entre essas descobertas, Paula narra em seu relato:

Por meio desta aula de campo, compreendi que ao fazer reflexões entre o passado e o presente, entendendo a relação existente entre eles estava exercendo meu "direito a memória", visto que, aqueles objetos eram repletos de significados e cultura, ou seja, representa o meu passado e minha história. (PAULA, 2017)

Nos relatos o museu também foi descoberto como espaço vivo:

O museu Solar Monjardim, de certa forma me encantou de uma forma especial, geralmente um museu é considerado um espaço "morto", com visitas repetitivas, carregado de longos discursos/apresentações dos objetos. Tivemos a oportunidade de realizar uma visita "viva", repleta de cuidados, preparação dedicação e afeto por parte dos expositores. Vimos naquele espaço um momento de grande aprendizagens e potencialização do ensino. (PAULO, 2017)

A narrativa acima nos remete à Chagas (2006), ao afirmar que "há uma gota de sangue em cada museu” (p. 29). A expressão sangue usada por Chagas (2006), traz para o museu a vida, o humano, um lugar que pulsa. Essa nova leitura apresentada no relato de Paulo (2017) contrapõe-se à representação recorrente do museu como espaço morto, neutro e apolítico, pois o museu é um lugar de aprendizagem, de fruição, de alegrias.

Outra questão que podemos pinçar à luz dos relatos são as reflexões que os alunos fizeram sobre a história, enquanto disciplina, e o estudo de campo em conexão com o seu tempo presente:

Ao estudar história na universidade consegui compreender questões que me intrigavam até aqui, questões que muitas vezes a escola, nem meus pais e muito menos a vida conseguiu esclarecer. Apesar de amar a história desde tenra idade, eu não compreendia o porquê precisávamos estudar essa disciplina. A partir das leituras do texto esses questionamentos foram sendo cessados pouco a pouco, porque a partir deles pude compreender que somente conhecendo o passado é que podemos compreender o presente, e que por meio do pensar historicamente nós podemos pensar nas manipulações históricas que nos foi apresentada. Os estudos de campo me proporcionou, também, um novo olhar.

Todavia, algo contribuiu muito em minha formação, não somente como pedagoga, mas sobretudo como humana e participante de uma historicidade nada abastada, de uma família simples de uma comunidade que vive às margens. Portanto, a forma como exploramos a disciplina de história neste penúltimo periodo de nossa formação, constituiu nossas práticas pedagógicas, para uma formação histórica dos sujeitos (ALESSANDRA, 2018). 
O relato da aluna vai ao encontro do que muito se tem pesquisado, debatido e produzido: a relação entre a teoria da história e o ensino de história. Essa relação se processa à medida que entendemos como dimensão da ciência especializada da história a relação que se estabelece da história com o cotidiano dos sujeitos históricos, com vistas para a orientação da vida prática. Orientação essencialmente ligada à ideia de identidade que passa pelo ambiente escolar e vai além dele. (BAROM; CERRI, 2011)

E por último, mas não menos importante, destacamos a relação museu/escola, assim explícita na narrativa abaixo:

\begin{abstract}
Ao entrarmos em contato com esses lugares devemos ter em mente que a ação educativa não se limita somente a exposição, ela deve extrapolar a exposição e chegar até a sala de aula. Dessa maneira, a escola tem que interagir com esses espaços, de forma mais frequente e não esporádica. Além do mais os guias ou até mesmo o professor devem encontrar os melhores meios de mediar a exposição, facilitando a compreensão, a percepção das informações expostas aos alunos contribuindo para que construam suas próprias significações, reflexões e conclusões (MARIA, 2017).
\end{abstract}

A narrativa da aluna nos convida a pensar na importância do ato de planejar as atividades que poderão ser desenvolvidas fora e dentro da escola. A ida a museus pode e deve ser lugar de entretenimento, mas não só isso. Sabemos como é difícil conseguir verbas para realizar atividades extrassala de aula. Portanto, não podemos deixar escorrer por entre os nossos dedos esses momentos tão ricos de aprendizagem.

\title{
Considerações, ainda que parciais
}

Os alunos do curso de Pedagogia fizeram seus próprios percursos no espaço museal e demonstraram que não são meros expectadores do que lhes era apresentado. Eles lembraram de visitas realizadas a esses espaços na educação básica, confrontaram experiências e memórias, fizeram relações com os textos debatidos em aula, e relacionaram com outras metodologias de ensino até então estudadas e vivenciadas em sua formação.

Dessa forma, visitar o museu é analisá-lo como ferramenta para visitas futuras, acompanhando seus próprios alunos. Ao ler os relatos destacamos a articulação dos saberes docentes, que também compõem a formação histórica, composta pelo amálgama de diversos saberes oriundos da formação profissional, dos saberes das disciplinas, dos currículos e da experiência (TARDIF, 2012). O amálgama desses saberes ajudou a compor o ato de olhar e ajudou na confecção dos sentidos produzidos nas narrativas contidas nos relatos. 
Os relatos das visitas demonstram uma leitura a "contra pelo", em vários momentos, da apresentada pelo monitor de museu, e podem ser vistos como trama tecida a partir da sensibilidade dos alunos do curso de Pedagogia a tudo o que lhes foi apresentado. Em suas competências narrativas aparecem os seus próprios sentidos históricos que atribuem em relação ao museu, à memória e à história. Uma narrativa que vai de encontro ao já estabelecido pelo poder institucionalizado.

Pertinente, nesse sentido, a narrativa de Silvia (2018), presente em seu relato, ao enfatizar que 'Ir ao museu Solar Monjardim me fez refletir sobre tudo aquilo que foi discutido nas aulas em dois olhares distintos: o de aluna (graduanda) e o de futura professora'.

E quiçá, reflexões geradoras de novas práticas...

\section{REFERÊNCIAS}

BAROM,W. C. C.; CERRI, L. F.O ensino da história a partir da teoria de JörnRüsen. Universidade Estadual de Maringá 2011. Disponível em: http://www.ppe.uem.br/publicacoes/seminario_ppe_2011/pdf/1/006.pdf. Acesso em: 20 abr. 2019.

CARVALHO, M. C.; PORTO, C. Crianças e Adultos em Museus e Centros Culturais. In: KRAMER, S.; NUNES, F.; CARVALHO, M. C. (org.). Educação Infantil: formação e responsabilidade. Campinas: Papirus, 2013. p. 133-150.

CHAGAS, M. S. A uma gota de sangue em cada museu. Chapecó: Argos, 2006.

CHARTIER, R. A história cultural: entre práticas e representações. Rio de Janeiro: Bertrand Brasil, 1990.

CHARTIER, R. A história ou a leitura do tempo. Belo Horizonte: Autêntica, 2009.

FENELÓN, D. R. Políticas Culturais e Patrimônio Histórico. In: FENELÓN, D. R. O direito à memória: patrimônio, história e cidadania. São Paulo: DPH, 1992.

MENESES, U. T. B. A história cativa da memória? Para um mapeamento da memória no campo das ciências sociais. Revista do Instituto de Estudos Brasileiros, São Paulo, n. 34, p. 9-24,1992.

MENESES, U. T. B. Educação e museus: sedução riscos e ilusões. Ciências; Letras, Porto Alegre, n. 27, p. 91-101, jan./jun. 2000.

ORIÁ, R. Memória e ensino de História. In: BITTENCOURT, C. (org.) O saber histórico na sala de aula. 12. ed. São Paulo: Contexto, 2013. p. 128-148.

POLLAK, M. Memória, esquecimento, silêncio. Estudos Históricos, Rio de Janeiro, v. 2, n. 3, p. 3-15, 1989. 
RAMOS, F. R. L. A danação do objeto: o museu no ensino de história. Chapecó: Argos, 2004.

RÜSEN, J. História Viva: teoria da história: formas e funções do conhecimento histórico. Brasília: UnB, 2007.

SIMAN, L. M. C. Práticas culturais e práticas escolares: aproximações e especificidades no ensino de história. Revista do Laboratório de Ensino de História/UEL, Londrina, v. 9, p. 185-204, 2003.

TARDIF, M. Saberes docentes e formação profissional. 13. ed. Rio de Janeiro: Vozes, 2012.

\section{Como referenciar este artigo}

BITTE, R. C. F.; SANTOS, S. M. Olhares sensíveis em estudo de campo ao museu Solar Monjardim: memória e formação histórica. Revista Ibero-Americana de Estudos em Educação, Araraquara, v. 16, n. 4, p. 2888-2902, out./dez. 2021. e-ISSN: 1982-5587. DOI: https://doi.org/10.21723/riaee.v16i4.14533

Submetido em: 08/07/2021

Revisões requeridas em: 10/08/2021

Aprovado em: $13 / 09 / 2021$

Publicado em: 21/10/2021 